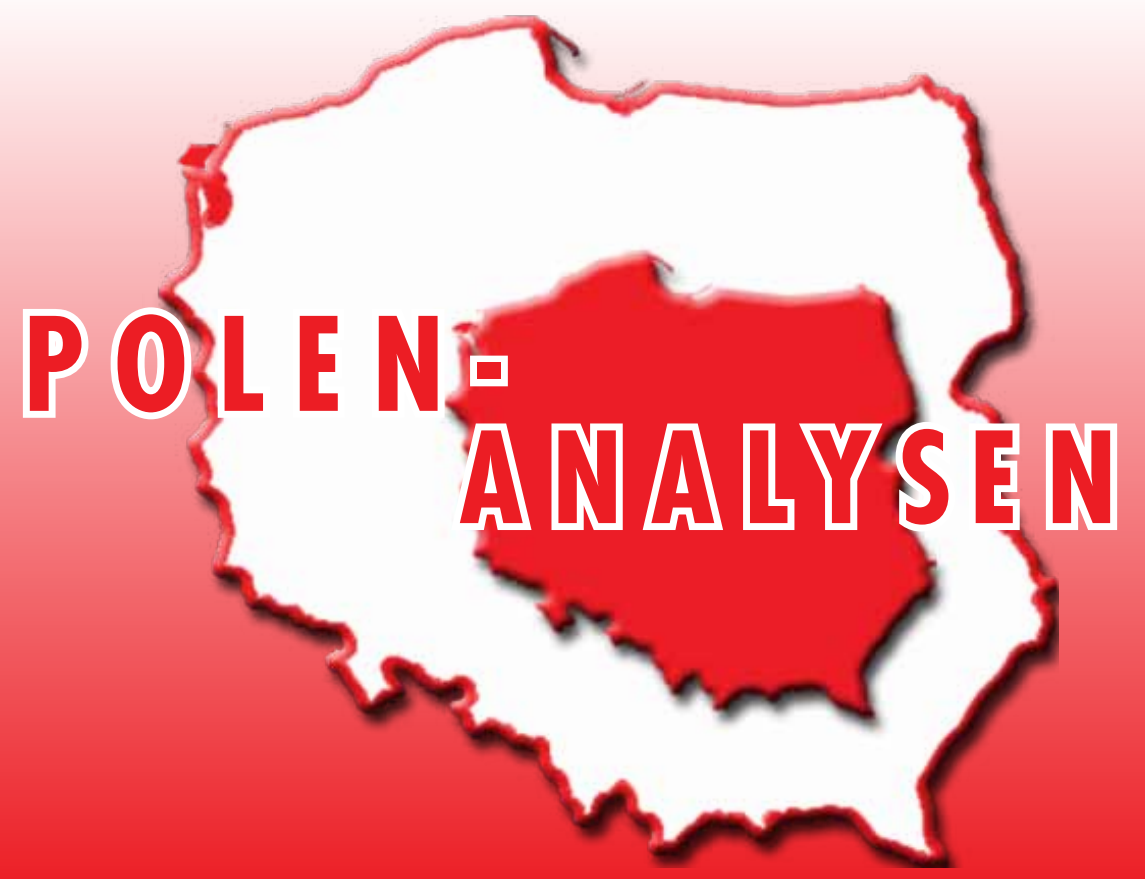

www.laender-analysen.de/polen

\title{
DIE PALIKOT-BEWEGUNG
}

\section{ANALYSE}

Die Palikot-Bewegung

Jarosław Flis, Krakau

- TABELLEN UND GRAFIKEN ZUM TEXT

Parteipräferenzen und Interessenvertretung

Einstellungen zur Regierung Tusk (Frühjahr 2012)

CHRONIK

Vom 17. bis zum 30. April 2012 


\section{Die Palikot-Bewegung}

Jarosław Flis, Krakau

\section{Zusammenfassung}

Die Palikot-Bewegung (Ruch Palikota) hat in den Parlamentswahlen 2011 einen überraschenden Wahlerfolg erzielt und ist drittstärkste Kraft im Sejm. Entstanden war sie erst im Sommer 2010, als es zum Bruch von Janusz Palikot mit seiner damaligen Partei $P O$ gekommen war, in der er intern sowie gegenüber anderen Parteien streitbare Positionen verfochten hatte. Die starke Seite der Palikot-Bewegung ist ihr Talent, die Sehnsucht nach einem modernen und effektiven Staat anzusprechen, und ihre Fähigkeit, sich an die Erwartungen des Infotainment anzupassen. Sie hätte die Chance, die Radikalisierung von PiS, die Ermüdung der Regierungspartei $P O$ und die Führungsschwäche in der $S L D$ für sich zu nutzen. Doch stehen die mangelnde Glaubwürdigkeit des Parteichefs und anderer Politiker, unklare politische Botschaften und die Unterordnung der Parteistrategie unter taktische Erwägungen ihren Ambitionen entgegen, eine dauerhaft prägende Kraft auf der politischen Bühne zu werden.

$\mathrm{D}$ ie Position der Palikot-Bewegung auf der politischen Bühne Polens lässt sich nicht verstehen, wenn man nicht Tatsachen und die Geschichte mitberücksichtigt, die schon im Jahr 2006 beginnen. Damals war gerade das Projekt einer gemeinsamen Regierung aus Bürgerplattform (Platforma Obywatelska-PO) und Recht und Gerechtigkeit (Prawo i Sprawiedliwość-PiS) gescheitert, das vor den Wahlen 2005 angekündigt worden war. Die $P O$ entschied sich, sich als prinzipielles Gegengewicht zu $P i S$ darzustellen. Die sich so positionierende $P O$ nahm einen großen Teil der politischen Landkarte Polens ein und siedelte sich auf der ökonomischen Achse als diejenige Gruppierung mit der wirtschaftlich liberalsten Haltung an (s. Grafik 1). Gleichzeitig umfasste sie ein sehr breites Spektrum auf der Achse der Wertefragen: Sie hatte auch ihren konservativen Flügel, aber - infolge des Konflikts mit PiS - vergrößerte sich auch die Unterstützung von Seiten eines Wählerspektrums, das der Tradition und der öffentlichen Rolle der Religion gegenüber kritisch eingestellt ist.

In diesem Koordinatensystem nahm Janusz Palikot als einer der führenden Köpfe der $P O$ eine Position auf ihrem linken Flügel ein, was Wertefragen betraf, und war dessen bekannteste Persönlichkeit. Dies bedeutete die größte Distanz zu der regierenden $P i S$, und es tauchten auch deutliche Akzente in Richtung einer Zusammenarbeit mit der Linken auf (was symbolisch darin Ausdruck fand, dass Palikot während des $P O$-Parteitags ein T-Shirt mit der Aufschrift »Ich bin aus der SLD« trug). Der Wahlerfolg der PO im Jahr 2007 war so groß, dass das linksliberale Bündnis Linke und Demokraten (Lewica i Demokraci-LiD), das sich um die Demokratische Linksallianz (Sojusz Lewicy Demokratycznej - SLD) gebildet hatte, in die Opposition gedrängt wurde und die PO gemeinsam mit der Polnischen Bauernpartei (Polskie Stronnictwo Ludowe - PSL) die Regierung bilden konnte.
Die Bildung einer solchen Regierung erlaubte, eine mittlere Position auf der Werteachse der polnischen Politik einzunehmen. Dies rief eine deutliche Enttäuschung einflussreicher Kreise hervor, die wirtschaftlichen Liberalismus mit einer linken Position auf der Werteachse verbanden, insbesondere also im Kreis um die Tageszeitung»Gazeta Wyborcza«. Das frustrierende Wahlergebnis von $L i D$ führte zu ihrem Zerfall und zu Veränderungen in der $S L D$-Führung, die in der Opposition blieb. Ihr Vorsitzender wurde Grzegorz Napieralski.

In dieser Zeit wurde Janusz Palikot Vorsitzender des Ausschusses »Freundschaftlicher Staat (Przyjazny Państwo), ein Leuchtturmprojekt der $P O$ in der neuen Legislaturperiode, das die Verschlankung des Staates zum Ziel hatte. Sieht man sich die internen Beziehungen in der $P O$ an, so blieb Palikot sowohl mit den Vertretern des rechten Flügels der $P O$, allen voran mit Jarosław Gowin, als auch mit dem einflussreichen Innenminister und stellvertretenden Ministerpräsidenten Grzegorz Schetyna im Konflikt. Charakteristisch für Janusz Palikot waren in dieser Zeit seine Verbalattacken gegenüber den führenden Köpfen von PiS, insbesondere Staatspräsident Lech Kaczyński. Dabei überschritt er sehr häufig die Grenzen des guten Geschmacks, unterstellte den Opponenten Alkoholismus oder verlangte öffentlich Auskunft über eine angeblich homosexuelle Neigung Jarosław Kaczyńskis.

Darüber hinaus begann Janusz Palikot, Happenings im Kontakt mit den Medien einzusetzen, bei denen er ebenfalls die Vorstellungen dessen, was sich gehört, überschritt. Ein solches Verhalten zog drei Arten von Reaktionen nach sich: Ein Teil des Personenkreises, der starke Antipathien gegenüber PiS und den Brüdern Kaczyński hegte, lobte ein derartiges Verhalten und bezeichnete es als »ehrlich". Ein Teil der $P O$-Politiker mit Ministerpräsident Donald Tusk an der Spitze zeigte sich ambivalent gegenüber den Aktionen Palikots; zwar sei das Verhalten nicht in Ord- 
nung, jedoch im Rahmen der Redefreiheit zuzulassen. Die dritte Reaktion waren öffentliche Entschuldigungen und Schambekundungen von Seiten der konservativen Vertreter der PO. Viele Gegner der PO unterstrichen, dass das Verhalten von Janusz Palikot zur Strategie der Partei gehöre und in vollkommenem Einvernehmen mit der Parteiführung zum Ausdruck komme. Dies bestätigte später übrigens der Betreffende selbst.

Ein wesentlicher Aspekt der Beziehungen innerhalb der $P O$ waren Konflikte, vor allem die sogenannte Glücksspielaffäre, die im Oktober 2009 zur Entlassung des stellvertretenden Ministerpräsidenten Grzegorz Schetyna führte. Zusammen mit den Begleitkommentaren von Janusz Palikot führte dieses Ereignis zu zunehmenden Spannungen zwischen ihm und dem immer noch einflussreichen Schetyna sowie Jarosław Gowin.

Die Spannungen in der Partei kulminierten im März 2010, als Ministerpräsident Donald Tusk darauf verzichtete, in den Präsidentschaftswahlen anzutreten und ein neuer Kandidat mit Hilfe von Vorwahlen bestimmt wurde. Janusz Palikot unterstützte eindeutig Bronisław Komorowski, obwohl dieser als Mensch mit konservativer Einstellung präsentiert wurde. Unterstrichen wurde aber dabei, dass er sich von den Hauptkonfliktlinien in der Partei fern halten würde und sicherlich auch nicht mit der Gruppe von eng zusammenarbeitenden Politikern auf dem konservativen Flügel der $P O$ assoziiert werden konnte. Jarosław Gowin unterstützte in den Vorwahlen Radosław Sikorski, der sie schließlich verlor. Janusz Palikot legte Radosław Sikorski gegenüber ein ähnliches Verhalten an den Tag wie zuvor gegenüber anderen Parteien. In seinem Blog suggerierte er, dass sich Sikorski nicht mit der Partei identifiziert und sie in die Spaltung führen wird. Dadurch heizte er die Spannungen in der $P O$ zusätzlich an und geriet in weitere Konflikte mit seinen Gegnern in der Partei.

Ein weiteres Schlüsselereignis für das politische Schicksal von Janusz Palikot war die Flugzeugkatastrophe von Smolensk im April 2010. In deren Folge kam es zu einer Veränderung in der Haltung Jarosław Kaczyńskis. Er bewegte sich auf die politische Mitte zu, reichte verschiedenen Milieus seine Hand zur Versöhnung und entschied sich, seine bisher konfrontative Rhetorik einzuschränken. Die Antwort von Seiten der $P O$ und insbesondere von Palikot war, die Ehrlichkeit dieses Verhaltens anzuzweifeln, und eine Eskalation von Äußerungen, die eine heftige Reaktion der PiS und die Aufgabe ihrer konzilianten Strategie herbeiführen sollte. Der Plan zeitigte nicht die erwünschten Ergebnisse, dennoch gewann Bronisław Komorowski die Präsidentschaftswahl. Dies aber erhöhte wiederum die Temperatur der Konflikte auf der politischen Bühne, wo einerseits öffentlich der Wille zur Zusammenarbeit kundgetan wurde, aber gleichzeitig im Hintergrund deutlich emotionalere und negativere Botschaften formuliert wurden.

So wuchsen gleichzeitig zwei Konflikte, einer in der $P O$ zwischen Palikot und den anderen Politikern, insbesondere mit Grzegorz Schetyna, der nach dem Wahlsieg von Bronisław Komorowski Sejmmarschall wurde. Der andere Konflikt war der mit PiS. Jarosław Kaczyński stellte nach den verlorenen Präsidentschaftswahlen seine gesamte vorherige Strategie in Frage und verschärfte entschieden seine Rhetorik. Ein wichtiges Element war hier der Streit um das Gedenkkreuz für die Opfer des Flugzeugunglücks von Smolensk, das vor dem Präsidentenpalast an der Krakowskie Przedmieście-Straße im Warschauer Zentrum aufgestellt worden war. Im August 2010 kam es zu einer spektakulären Eskalation dieses Konflikts. Janusz Palikot, bedrängt von internen Spannungen in der $P O$, verkündete angesichts des heftigen Anstiegs der Emotionen um das Kreuz und der Sichtbarwerdung antiklerikaler Bewegungen die Gründung einer eigenen Bewegung, an deren Spitze er selbst zu stehen gedachte.

Gleich nach Abklingen des Sturms um das Gedenkkreuz kam es zum Gründungskongress der Palikot-Bewegung, deren Gründer auf seine Mitgliedschaft in der $P O$ verzichtete. Allerdings gelang es nicht, bedeutende Politiker in diese Initiative mit zu integrieren, weder aus der $P O$ noch aus der Linken, trotz verschiedener Spekulationen in diese Richtung. Palikot selbst gab sein Abgeordnetenmandat zurück.

Die Palikot-Bewegung existierte in den Umfragen allerdings nicht. Ende 2010 und noch viele Monate im Jahr 2011 balancierte die neue Gruppierung an der Grenze eines statistischen Irrtums. Der Schlüssel zum Verstehen der Bedingungen, unter denen es zum Erfolg der Palikot-Bewegung kommen konnte, ist die Position von Grzegorz Napieralski als SLD-Vorsitzender. Anfang 2011 fiel die $P O$ infolge einiger krisenhafter Situationen und dadurch bedingter weiterer interner Spannungen in den Umfragen zurück. Zu einem bestimmten Zeitpunkt zeigten die Umfragen, dass die SLD gegenüber der größten Oppositionspartei, PiS, aufholt. Diese Tendenz schien sich zu verstärken. Der einzige Effekt war dann allerdings das steigende Selbstbewusstsein des jungen $S L D$-Chefs, der es zu einer Reihe von Konflikten mit anderen Akteuren in seiner Partei kommen ließ, die er als Konkurrenz in Sachen Führung betrachtete. Dies führte zu einer Schwächung der Partei kurz vor dem Wahlkampf; einige wichtige Politiker der Linken begannen, mit der $P O$ zusammenzuarbeiten. Dies war eine doppelte Schwächung Napieralskis, denn es zwang ihn zu Zugeständnissen denjenigen gegenüber, die in der Partei geblieben waren. Diese Schwächung verstärkte sich noch durch die öffentlich geäußerten Zweifel an ihm von Seiten des einflussreichen Akteurs 
der Linken, des ehemaligen Staatspräsidenten Aleksander Kwaśniewski.

Auf den Wahllisten der $S L D$ gab es keine Plätze für den Kreis von Akteuren der Linken, denen der Führer der neuen Bewegung, Palikot, einen zwar riskanten, aber immerhin nicht chancenlosen Start anbieten konnte. In Hinblick auf die Umfragewerte der $S L D$ konnte eh nur davon ausgegangen werden, dass die Partei ein, maximal zwei Mandate in bestimmten Wahlkreisen erhalten würde. Die Palikot-Bewegung hatte dagegen überhaupt keine bekannten Persönlichkeiten, die von ihrer Liste hätten starten können, daher war eine große Freizügigkeit bei der Vergabe der ersten Listenplätze möglich. Diese Plätze gaben im Falle eines Einzugs ins Parlament denjenigen die größten Chancen auf ein Mandat, die nicht mit einer Führungsposition in der SLD rechnen konnten. Auf diese Weise kamen Akteure wie beispielsweise die Feministin Wanda Nowicka, Robert Biedroń, führender Kopf der »Kampagne gegen Homophobie«, Anna Grodzka, transsexuelle gesellschaftliche Aktivistin, oder Andrzej Rozenek, stellvertretender Chefredakteur der Wochenzeitschrift »Nie», die im postkommunistischen Milieu eine wichtige Rolle spielt, auf die Liste der Palikot-Bewegung. Auf den Wahllisten befand sich auch eine so kontroverse Person wie Marek Kotliński, ein ehemaliger katholischer Priester, jetzt Chefredakteur der antiklerikalen Zeitschrift "Fakty i Mity».

Trotzdem oszillierten die Umfragewerte der PalikotBewegung zu Beginn des Wahlkampfes noch um den Wert eines Messfehlers herum und ließen einen Einzug in den Sejm weit entfernt erscheinen. Der Erfolg dieser Gruppierung setzte wortwörtlich in letzter Minute ein. In der letzten Woche vor den Wahlen erschienen Prognosen, die die Möglichkeit ihres Einzugs voraussagten. Außerdem konzentrierten sich auch die anderen Parteien auf die Palikot-Bewegung: PiS attackierte die PO, indem sie auf die Wahrscheinlichkeit hinwies, dass es zu einer Koalitionsvereinbarung zwischen der Regierungspartei $P O$ und der Palikot-Bewegung kommen könne. Das Ziel dabei war, Wähler vom rechten Rand der $P O$ zur Stimmabgabe für $P i S$ zu gewinnen.

Zusammengefasst: Die Entstehung und Gründung der Palikot-Bewegung war ein Ergebnis vorangegangener Spannungen zwischen und innerhalb der bestehenden Parteien. Diese Spannungen drückten die neue Gruppierung zwar aus dem Regierungslager heraus, boten dann aber die Chance eines Wahlerfolgs - diese Chance hat die Palikot-Bewegung genutzt.

\section{Die Palikot-Bewegung im Sejm}

Eine nähere Analyse des Wahlergebnisses birgt gewisse Schwierigkeiten, denn die Befragten, die für die PalikotBewegung gestimmt hatten, gaben an, früher $P O$ gewählt zu haben. Dies könnte auf die Hauptrichtung der Wählerabwanderung hinweisen. Der Erfolg der neuen Gruppierung könnte dann damit erklärt werden, dass $P O$ die Position des Verteidigers des status quo übernommen hat, sowie mit fehlenden Erfolgen auf dem Feld der wirtschaftlichen Deregulierung. Allerdings zeigt die vergleichende Analyse der Ergebnisse verschiedener Parteien auf der Ebene der Wahlkreise, dass die eindeutig stärkere Quelle für die Palikot-Bewegung die Wählerschaft von $L i D$ aus dem Jahr 2007 war. Die Analyse zeigt, dass die Hälfte der Wähler der Palikot-Bewegung Wähler von $L i D$ waren und weniger als ein Sechstel Wähler der $P O$. Der Verlust der Unterstützung letzterer in der Wahl 2011 war deutlich geringer als die Verluste der $S L D$. Jedenfalls situiert sich diese neue Bewegung zweifellos in der linken oberen Ecke der bereits angeführten Grafik.

Die Palikot-Bewegung erlangte 40 Mandate und ist die drittgrößte Fraktion im Sejm. Dennoch war der Erfolg der neuen Gruppierung auch nicht so groß, als dass die nur minimal geschwächten $P O$ und $P S L$ ihre Mehrheit im Sejm nicht hätten behalten können. Demzufolge befindet sich die Palikot-Bewegung in der Opposition.

Die Spekulationen um ihre Ausgangsposition wiesen zwei wesentliche Optionen auf. Erstens, dass die Palikot-Bewegung anstelle der PSL ein alternativer Koalitionspartner für die $P O$ werden könnte, was eine Umsetzung liberaler Projekte ermöglichen könnte, für die die $P S L$ bisher die regierungsinterne Opposition gewesen war. Zweitens kam die Frage auf, ob die PalikotBewegung nicht letzten Endes in Gänze die Aktiva der $S L D$ übernehmen würde, die von ihrer Wahlniederlage geschwächt war. Die $S L D$ gewann nur die Hälfte der Sitze, die sie vorher innehatte, was Grzegorz Napieralski als Parteichef vollständig kompromittierte. Er übernahm dafür die Verantwortung und verzichtete auf das Amt des Vorsitzenden.

Als Problem erwies sich, dass es keinen alternativen Kandidaten für den $S L D$-Vorsitz gab. Die Suche nach einem neuen Vorsitzenden endete bei dem ehemaligen Ministerpräsidenten Leszek Miller, der 2003 vom Amt des Regierungschefs in einer skandalumwitterten Atmosphäre zurückgetreten war und dessen späteres politisches Schicksal seine vollständige Marginalisierung zu bestätigen schien.

Die Beziehungen zwischen den Parteien der linken Opposition im Sejm gestalteten sich nicht gut; es trennte sie beispielsweise der Streit um den Bezug hochwertiger Büros. Außerdem hatte jede von ihnen vollkommen andere Ambitionen und eine andere organisatorische Basis. Auch unterschied sie die Anzahl der erfahrenen Akteure in der zweiten Reihe sowie die Position auf der 
Ebene der Selbstverwaltung - die Politiker der SLD besetzen zwar nicht viele, aber doch einige Positionen in Woiwodschaftsverwaltungen und einige Ämter als Stadtpräsidenten.

Nach dem überraschenden Wahlsieg standen vor der Palikot-Bewegung fundamentale Dilemmata. Die grundsätzliche Frage war, in welcher Richtung Wählerschaft hinzugewonnen werden sollte, wollte man doch aus der Ecke herauskommen, die von Extrempositionen im Bereich von Wertefragen und von wirtschaftlichen Fragen gekennzeichnet war. Möglich war nun, sich in Richtung Zentrum zu bewegen, indem die Aussagen in jenen beiden Bereichen abgemildert wurden. Möglich war aber auch, zu versuchen, das Monopol in der Linken zu übernehmen und dafür auf der Achse der Wertefragen auf einer Außenposition zu bleiben, während auf der Wirtschaftsachse die Sorge um sozial Schwache, das regulierende Eingreifen des Staates im Bereich des wirtschaftlichen Umsatzes, die Aufstockung der Sozialtransfers usw. mehr in den Vordergrund rücken müssten.

Bis heute ist hier das Fehlen einer eindeutigen Botschaft feststellbar. Einerseits nimmt die Palikot-Bewegung an Initiativen teil, die die Linke in Wertefragen vereinen und ihre verschiedenen Flügel im Bereich Wirtschaftspolitik zusammenführen sollen. Solche Initiativen werden unter der Schirmherrschaft von Aleksander Kwaśniewski unternommen, der hier eindeutig einen Platz für die Palikot-Bewegung sieht. Aus seiner persönlichen Vorliebe resultiert der Wunsch, zur Formulierung Linke und Demokraten zurückzukehren und die Spaltung der Parteienlandschaft (postkommunistischpost-Solidarność) zu überwinden, und insbesondere die Palikot-Bewegung soll ein Element des Puzzles sein. Andererseits werden derlei Initiativen seitens der SLD mit deutlichem Missfallen aufgenommen. Die Erfahrung mit LiD im Jahr 2007 wird als Niederlage der SLD und Schwächung der Partei gewertet, daher auch das deutlich fehlende Engagement von Leszek Miller.

Zwei konkrete Angelegenheiten spalteten die Parteien im Sejm, die sich als links bezeichnen. Die eine ist die Rentenreform. Die SLD stand eindeutig in Opposition zu den Plänen der Regierung und stellte sich als Verteidiger der Beute des Sozialstaates dar. Die Haltung der Palikot-Bewegung war dagegen nicht eindeutig - der Wunsch, mit der SLD zu rivalisieren und sie an den Rand zu drängen, bewegte sie dazu, soziale Forderungen zu erheben und die Regierungsentwürfe abzumildern. Andererseits tauchte aber auch die Versuchung auf, die Regierungskoalition zu zerschlagen. Der Koalitionspartner PSL bekundete Zweifel an den Forderungen des Ministerpräsidenten und der $P O$. In der öffentlichen Debatte kam die Vision auf, die PSL durch die Palikot-Bewegung zu ersetzen, die dann in einer Regie- rungskoalition als die Partei auftreten würde, die die liberalen Vorschläge akzeptieren würde.

Dieses Spiel gründet auch auf politischer Taktik, auf dem Wunsch, der PO ihre dominierende Position zu entziehen, indem eine politische Destabilisierung herbeigeführt wird. Stabilisierung war einer der Trümpfe, der für den Wahlerfolg der PO im Jahr 2011 wesentliche Bedeutung hatte.

Die fehlende Eindeutigkeit der Palikot-Bewegung, ihre wechselnden Präferenzen und Botschaften, die die politische Taktik auf Kosten einer eindeutigen strategischen Orientierung hervorhoben, brachten keinen Nutzen, vielmehr zeichneten sich Verluste in den Umfragen ab. Das Gefühl, auf einem aufstrebenden Ast zu sein, das die Palikot-Bewegung direkt nach den Wahlen begleitet hatte, erlosch. Ausdruck dessen waren die Parteiübertritte eines $S L D$ - und eines $P O$-Abgeordneten in die Palikot-Bewegung gewesen. Die Ankündigungen in den Medien von weiteren Übertritten aus diesen Parteien haben sich nicht bestätigt.

Das zweite Konfliktfeld waren die Gefängnisse des CIA, die in Polen unter der Regierung von Leszek Miller in Dienst genommen worden waren. Dies war eine Gelegenheit für Janusz Palikot, den ehemaligen Ministerpräsidenten scharf zu attackieren, was sich in einem breiten Medienecho niederschlug. Allerdings teilten in den meisten Fällen nicht einmal die Milieus, die die Palikot-Bewegung gerade in dieser Angelegenheit unterstützten, seine Position. Zu seinen Attacken verhielten sie sich eher skeptisch und nahmen zweifelsohne eine ausgewogenere Haltung ein.

Theoretisch wäre die Koexistenz zweier Parteien auf der linken Seite der politischen Bühne Polens möglich, einer wirtschaftlich eher liberalen und einer stärker sozialen. Das Hindernis ist hier die Frage der Ambitionen. Die Wahrscheinlichkeit ist gering, dass diese beiden Parteien gleichgewichtig wären. Das würde eine schädliche Rivalität bedeuten, die aus institutionellen Interessen oder persönlichem Ehrgeiz resultieren würde. Andererseits würde gegen diese Lösung die Wahlarithmetik sprechen. Im polnischen Wahlsystem führt eine Teilung in zwei Gruppierungen unvermeidlich zu einer mathematischen Schwächung, was die Anzahl der Mandate im Verhältnis zur erhaltenen Unterstützung betrifft.

\section{Stärken und Schwächen, Chancen und Gefahren}

Man kann sagen, dass die starke Seite der Palikot-Bewegung ihr Talent ist, die Sehnsucht nach einem modernen und effektiven Staat ausnutzen. Dieses Bedürfnis hatte vorher die $P O$ für sich genutzt, aber mit Ausübung des Regierungsamtes, der unvermeidlichen Bewegung in Richtung Zentrum und Zweifeln an der Effektivität 
der Partei traten immer größere Unsicherheiten in der Wählerschaft der $P O$ auf, ob dies tatsächlich die Partei ist, die diese Sehnsucht befriedigen kann. Eine weitere starke Seite der Palikot-Bewegung ist ihr Medientalent, d. h. ihre Fähigkeit, sich an die Erwartungen des Infotainment anzupassen. Entscheidend ist dafür die vollständige Akzeptanz der Logik der Medien, die an emotionalen Botschaften, Konflikten, Skandalen und Kontroversen interessiert sind. Über den Erfolg der Palikot-Bewegung entschied aber nicht nur, dass sie sich in die Medien durchgeschlagen und die Sympathie der Journalisten erlangt hat, sondern auch, dass sie sich außerhalb der Medien bewegt und sich bewusst ist, dass das politische Leben nicht nur im Fernsehstudio gestaltet wird. Dieser Erfolg wäre ohne intensive Aktivitäten auf lokaler Ebene, in Form von Veranstaltungen in Kleinstädten und des Aufbaus verzweigter Strukturen, nicht möglich gewesen.

Eine Chance für die Palikot-Bewegung ist die Radikalisierung von PiS. Das macht PiS einerseits weniger gefährlich, in Zukunft die Regierung zu übernehmen, was wiederum einer Polarisierung in Richtung ZweiParteien-System entgegenwirkt. Andererseits wecken die Radikalisierung der PiS-Botschaften, die Bezugnahme auf die Religion und die offene Feindschaft gegenüber Gegnern das Bedürfnis nach Antiklerikalismus unter den PiS-Gegnern und danach, deutliche Antipathie gegenüber PiS zum Ausdruck zu bringen. Eine weitere Chance für die Palikot-Bewegung ist auch die Ermüdung der $P O$ und die Konsequenzen dessen, eine Partei der Macht geworden zu sein, die ihre Unterstützung nicht mehr auf Aufruhr und Hoffnung auf Veränderung gründet, sondern auf der Akzeptanz des status quo. Nicht ohne Bedeutung sind für die Palikot-Bewegung außerdem die Schwächen der SLD, insbesondere die Schwäche der Parteiführung, in der keine Persönlichkeit zu sehen ist, die den unbestrittenen Trumpf in der Hand hält, um die Wählergunst zu gewinnen. Eine Chance ist außerdem der Wahlkalender - die Europawahlen (2014) und vor allem auch die Präsidentschaftswahlen in Polen (2015) können eine Gelegenheit sein, mit neuen Initiativen die Unterstützung seitens der Wähler auszubauen.

$\mathrm{Zu}$ den Schwächen der Palikot-Bewegung gehört die mangelnde Glaubwürdigkeit ihres Parteichefs selbst. Palikot liefert sich regelmäßig mit Jarosław Kaczyński einen „Kampf« um die letzten Plätze bei Umfragen zum Vertrauen gegenüber Politikern. Sein politischer Lebenslauf weist zahlreiche schwache Punkte auf, beispielsweise die zurückliegende Gründung der radikal-konservativen Zeitung »Ozon«, der Erwerb von Vermögen durch die Produktion von Obstweinen, was sich kaum als prestigeträchtiges Unternehmen bezeichnen lässt, das Auslagern von Vermögen in "Steuerparadiese« und der Prozess mit seiner Exfrau in diesem Zusammenhang - all dies wird immer wieder von seinen Gegnern in Erinnerung gebracht. Wiederkehrend sind auch die Bedenken hinsichtlich der Finanzierungsquellen seines Wahlkampfes, als er noch von der Liste der $P O$ startete, sowie der zahlreichen Indiskretionen, die er in seinem Buch beging, in dem er Privatgespräche wiedergab. Dabei sparte er nicht an persönlichen und nicht überprüfbaren Beschuldigungen gegenüber seinen Parteikollegen aus der $P O$ und anderen Personen der rechten und linken politischen Szene, mit denen er Kontakte unterhielt. Ein weiteres Problem ist auch die Widersprüchlichkeit seines Auftretens. Auf der einen Seite baut er seine Botschaft auf einer AntiEstablishment-Haltung auf, auf dem Protest gegen die bisherige Politik, auf der anderen Seite pflegt er sehr gute Beziehungen mit Medienstars und dem doch so kritisierten Establishment, zu dem er selbst lange Jahre gehörte.

Eine Schwäche der Palikot-Bewegung ist die Unberechenbarkeit der Politiker der zweiten Reihe, unter denen sich viele mit einer sehr kontroversen Biographie befinden. Die Liste der Schwächen wird schließlich von der fehlenden Konsequenz im Bereich der Parteistrategie und der Unterordnung strategischer Entscheidungen unter die aktuelle Taktik vervollständigt. Eine Erklärung dafür könnte die Abhängigkeit von den Medien sein, davon, dass die eigene Position über Medienkontakte aufgebaut wird, weshalb die eigenen politischen Initiativen der Notwendigkeit untergeordnet werden, dass man in den Medien wahrgenommen wird.

Ein Problem ist darüber hinaus die Tatsache, dass die ganze Gruppierung von Janusz Palikot um seine Führungsperson herum aufgebaut ist und die übrigen bekannten Personen in dieser Partei eindeutige Bedenken auch unter Sympathisanten hervorrufen. Ein solcher Einzelspieler hat Schwierigkeiten, seine Botschaft zu differenzieren, mit unterschiedlichen Flügeln zu spielen, die Wählerschaft zu erweitern, indem bestimmten Wählergruppen bestimmte »Botschafter« innerhalb der Partei zugeordnet werden. Darüber hinaus ist es langfristig auch eine Gefahr für die Kohärenz der Gruppierung, wenn ihr charakteristische Persönlichkeiten fehlen. Solange eine Partei auf Entwicklung zählen kann, kann sie auch mit der Loyalität ihrer Mitglieder rechnen. Sollten aber irgendwelche Bedenken aufkommen, was auch schon bei anderen Protestparteien in Polen der Fall war, zum Beispiel bei Selbstverteidigung (Samoobrona), dann kann es sehr leicht zu internen Konflikten und Spaltungen kommen, was den Wechsel einzelner Akteure zu anderen Parteien nach sich ziehen kann. Eine Gefahr, die von außen auftritt, können die Selbstverwaltungswahlen sein, die in naher Zukunft stattfinden werden und eine große Herausforderung für eine Partei darstellen, die trotz allem lokal sehr schwach verwurzelt ist. 
Heute ist es schwer vorstellbar, dass die Palikot-Bewegung eine dauerhaft prägende Kraft auf der politischen Bühne Polens werden wird, obwohl genau dies die aktuelle Botschaft des Parteiführers ist. Wahrscheinlicher ist, dass sie ähnliche Schwierigkeiten wie Selbstverteidigung durchmachen wird - eine andere Partei, die gegen den status quo mit einer Anti-Establishment-Rhetorik anging und nach einigen Jahren Anwesenheit in der Politik der vollkommenen Zerstörung anheimfiel. Im Vergleich mit Selbstverteidigung hat die Palikot-Bewegung allerdings eine deutlich stärkere Position inne - vor allem aufgrund der Sympathie einiger einflussreicher Medien. Das kann bedeuten, dass sie einen dauerhaften Platz in der Politik einnehmen wird, als eine Gruppierung, die sowohl in Werte- als auch in Wirtschaftsfragen liberal ist und die ihre Nische finden wird, wenn nicht gar ihr Potential, als Koalitionspartner zu agieren. Bis dahin muss aber noch eine Probe bestanden werden, und zwar eine besonders schwierige Probe. In den Jahren 2014/15 wird eine Reihe von Wahlen stattfinden, angefangen mit der Europawahl über die Selbstverwaltungswahlen, die Präsidentschaftswahlen und schließlich die entscheidende, die Parlamentswahl. Diese Probe stellte eine grundsätzliche Herausforderung für die neue Gruppierung dar. Sie kann ihre Position bestätigen und ein Schlüsselelement in den Koalitionsspielchen werden. Es kann sich aber auch zeigen, dass eine solche Probe ihre organisatorischen Fähigkeiten und auch ihr politisches Konzept übersteigt. Die aktuelle Phase der politischen Stabilisierung muss als Vorbereitung auf die bevorstehende Probe gewertet werden. Unschlüssigkeit und Entscheidungen von heute können für die Wahlergebnisse im Jahr 2015 ähnlich entscheidend sein, wie die vermeintlich fernen Konsequenzen und zweitrangigen Fehler der Konkurrenz, die über den Erfolg der Palikot-Bewegung in den Wahlen von 2011 entschieden haben.

Übersetzung aus dem Polnischen: Silke Plate

\section{Über den Autor}

Dr. Jarosław Flis ist Soziologe am Institut für Journalistik und gesellschaftliche Kommunikation an der JagiellonenUniversität in Krakau (Uniwersytet Jagielloński, Kraków). Seine Forschungsschwerpunkte sind Public Relations, Soziologie der Politik und Verwaltung öffentlicher Institutionen. Er verfasst regelmäßig Beiträge und Kommentare u.a. für die Zeitungen Gazeta Wyborcza, Rzeczpospolita, Tygodnik Powszechny sowie für die Fernsehsender TVP und TVN.

\section{Parteipräferenzen und Interessenvertretung}

\section{Grafik 1: Schwerpunkte der Wählerschaften der Parlamentswahlen 2007-2011}

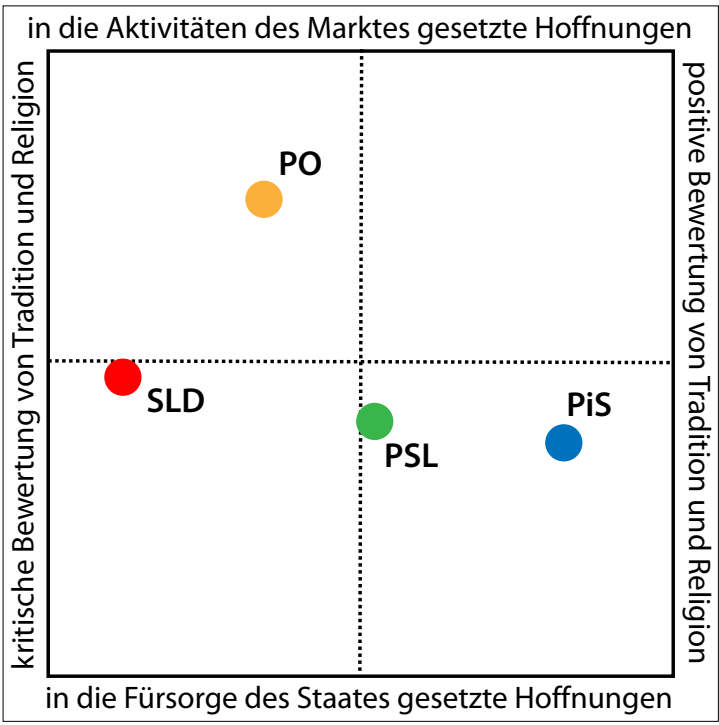

\footnotetext{
Erstellt von Jarosław Flis auf der Basis von: CBOS: Elektoraty partyjne o istotnych kwestiach społeczno-politycznych [Wählerschaften über wesentliche gesellschaftspolitische Fragen], Warszawa 09/2011; Elektoraty gtównych partii politycznych: charakterystyka pogladów [Wählerschaften der größten Parteien: Charakterisierung ihrer Ansichten], Warszawa 10/2009; Spotecznopolityczne postawy Polaków [Die gesellschaftspolitischen Einstellungen der Polen], Warszawa 12/2007.
} 
Grafik 2: Wen würden Sie wählen, wenn am Sonntag gewählt würde? (\%)*

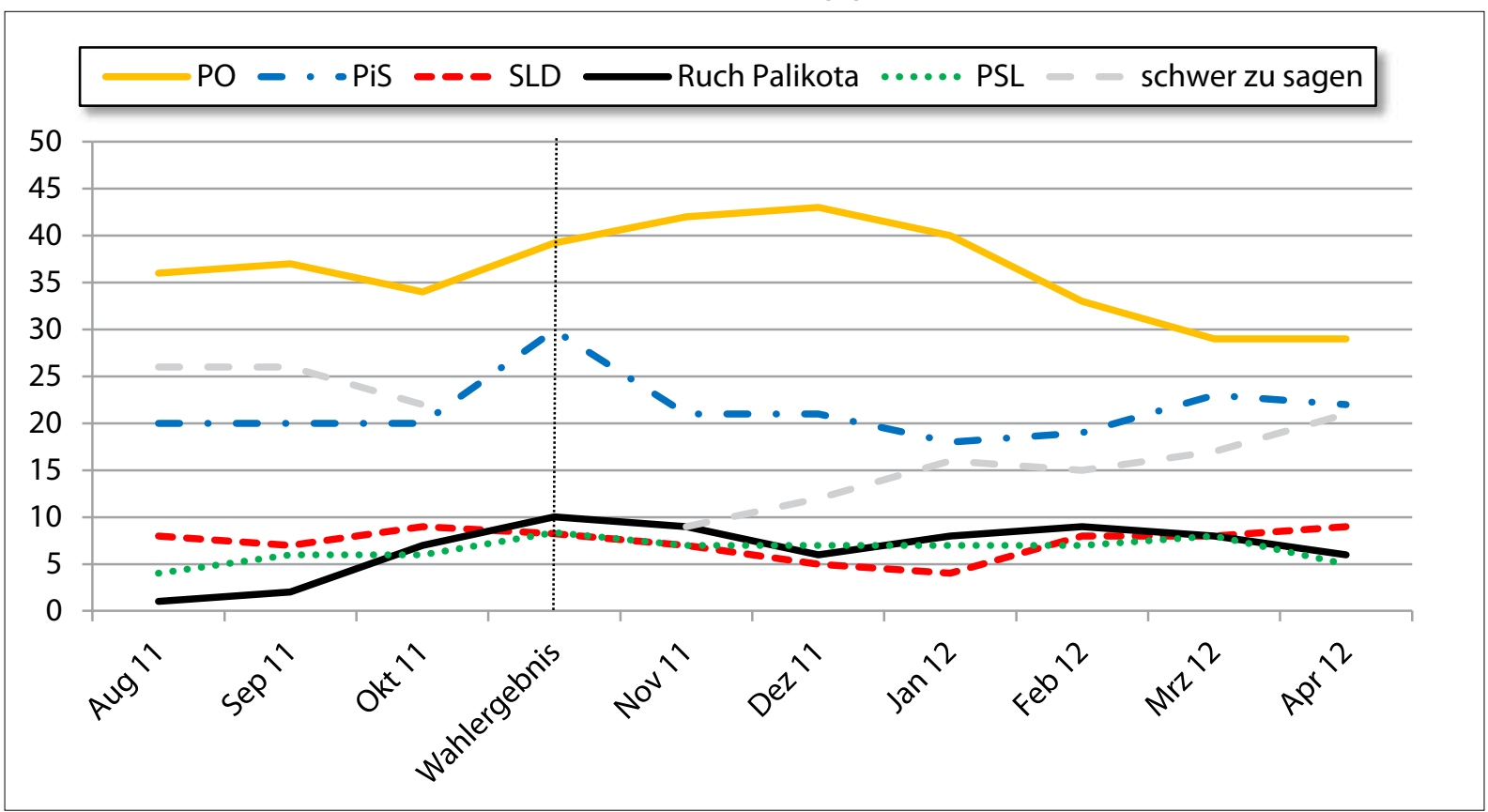

*Ausgewertet wurden die Antworten derer, die angaben, zur Wahl zu gehen.

PO-Platforma Obywatelska-Bürgerplattform; PiS-Prawo i Sprawiedliwość-Recht und Gerechtigkeit; SLD - Sojusz Lewicy Demokratycznej-Demokratische Linksallianz; Ruch Palikota-Palikot-Bewegung; PSL - Polskie Stronnictwo Ludowe - Polnische Bauernpartei Quelle: CBOS, BS/53/2012: Preferencje partyjne w kwietniu [Parteipräferenzen im April]. Warszawa 04/2012. www.cbos.pl

Tabelle 1. Wen würden Sie wählen, wenn am Sonntag gewählt würde? (\%)*

\begin{tabular}{|c|c|c|c|c|c|c|c|c|c|c|}
\hline & $08 / 2011$ & $09 / 2011$ & $10 / 2011$ & $\begin{array}{l}\text { Wahl- } \\
\text { ergebnis }\end{array}$ & $11 / 2011$ & $12 / 2011$ & $1 / 2012$ & $2 / 2012$ & $3 / 2012$ & $4 / 2012$ \\
\hline $\mathrm{PO}$ & 36 & 37 & 34 & 39,18 & 42 & 43 & 40 & 33 & 29 & 29 \\
\hline $\mathrm{PiS}$ & 20 & 20 & 20 & 29,89 & 21 & 21 & 18 & 19 & 23 & 22 \\
\hline SLD & 8 & 7 & 9 & 8,24 & 7 & 5 & 4 & 8 & 8 & 9 \\
\hline Ruch Palikota & 1 & 2 & 7 & 10,02 & 9 & 6 & 8 & 9 & 8 & 6 \\
\hline PSL & 4 & 6 & 6 & 8,36 & 7 & 7 & 7 & 7 & 8 & 5 \\
\hline Solidarna Polska & - & - & - & - & - & 2 & 2 & 3 & 3 & 4 \\
\hline $\begin{array}{l}\text { Nowa Prawica } \\
\text { Janusza Korwin- } \\
\text { Mikkego** }^{*}\end{array}$ & 0 & - & - & 1,06 & 1 & 1 & 2 & 2 & 2 & 3 \\
\hline PJN & 0 & 1 & 1 & 2,19 & 2 & 1 & 1 & 2 & 0 & 1 \\
\hline $\begin{array}{l}\text { Prawica Rzeczy- } \\
\text { pospolitej }\end{array}$ & 0 & - & - & 0,24 & 1 & 0 & 0 & 0 & 1 & 0 \\
\hline PPP & 0 & 0 & 1 & 0,55 & 0 & 0 & 0 & 1 & 0 & 0 \\
\hline andere & 0 & 1 & 1 & 0,26 & 1 & 1 & 1 & 2 & 1 & 1 \\
\hline schwer zu sagen & 26 & 26 & 22 & - & 9 & 12 & 16 & 15 & 17 & 21 \\
\hline
\end{tabular}

\section{*Ausgewertet wurden die Antworten derer, die angaben, zur Wabl zu gehen.}

PO-Platforma Obywatelska - Bürgerplattform; PiS - Prawo i Sprawiedliwość-Recht und Gerechtigkeit; SLD - Sojusz Lewicy Demokratycznej - Demokratische Linksallianz; Ruch Palikota - Palikot-Bewegung; PSL - Polskie Stronnictwo Ludowe - Polnische Bauernpartei; Solidarna Polska - Solidarisches Polen; **Nowa Prawica Janusza Korwin-Mikkego - Neue Rechte von Janusz Korwin-Mikke (bis 08/2011 Unterstützung für Unia Polityki Realnej - Union für Realpolitik); PJN - Polska Jest Najważniejsza - Polen ist das Wichtigste; Prawica Rzeczypospolitej - Rechte der Republik; PPP - Polska Partia Pracy - Polnische Partei der Arbeit

Quelle: CBOS, BS/53/2012: Preferencje partyjne w kwietniu [Parteipräferenzen im April]. Warszawa 04/2012. www.cbos.pl 
Grafik 3: In welchem Maß vertreten die genannten Parteien Ihre Interessen und Ansichten?* (\%)

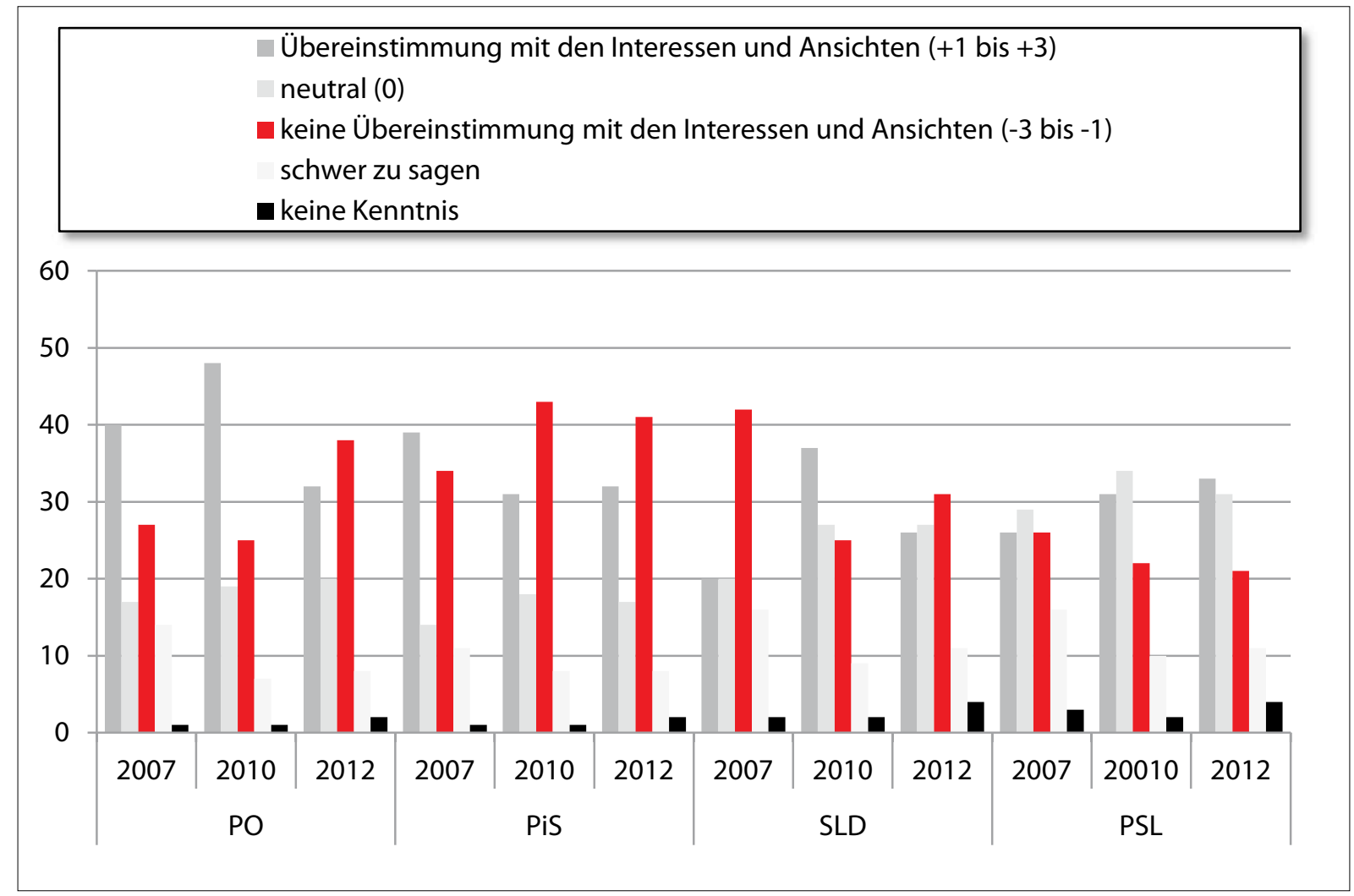

*Einordnung auf einer Skala von -3 bis $-1 ; 0 ;+1$ bis +3

PO-Platforma Obywatelska - Bürgerplattform; PiS - Prawo i Sprawiedliwość-Recht und Gerechtigkeit; SLD - Sojusz Lewicy Demokratycznej - Demokratische Linksallianz; PSL - Polskie Stronnictwo Ludowe - Polnische Bauernpartei

Quelle: CBOS BS/56/2012 Reprezentatywność partii politycznych [Die Repräsentativität der politischen Parteien]. Warszawa 04/2012. www.cbos.pl

Tabelle 2: In welchem Maß vertreten die genannten Parteien Ihre Interessen und Ansichten?* (\%)

\begin{tabular}{|c|c|c|c|c|c|c|c|c|c|c|c|c|}
\hline & \multicolumn{3}{|c|}{ PO } & \multicolumn{3}{|c|}{$\mathrm{PiS}$} & \multicolumn{3}{|c|}{ SLD } & \multicolumn{3}{|c|}{ PSL } \\
\hline & 2007 & 2010 & 2012 & 2007 & 2010 & 2012 & 2007 & 2010 & 2012 & 2007 & 20010 & 2012 \\
\hline $\begin{array}{l}\text { Übereinstimmung } \\
\text { mit den Interessen } \\
\text { und Ansichten }(+1 \\
\text { bis }+3)\end{array}$ & 40 & 48 & 32 & 39 & 31 & 32 & 20 & 37 & 26 & 26 & 31 & 33 \\
\hline neutral $(0)$ & 17 & 19 & 20 & 14 & 18 & 17 & 20 & 27 & 27 & 29 & 34 & 31 \\
\hline $\begin{array}{l}\text { keine Überein- } \\
\text { stimmung mit } \\
\text { den Interessen } \\
\text { und Ansichten (-3 } \\
\text { bis -1) }\end{array}$ & 27 & 25 & 38 & 34 & 43 & 41 & 42 & 25 & 31 & 26 & 22 & 21 \\
\hline schwer zu sagen & 14 & 7 & 8 & 11 & 8 & 8 & 16 & 9 & 11 & 16 & 10 & 11 \\
\hline keine Kenntnis & 1 & 1 & 2 & 1 & 1 & 2 & 2 & 2 & 4 & 3 & 2 & 4 \\
\hline
\end{tabular}

${ }^{*}$ Einordnung auf einer Skala von -3 bis $-1 ; 0 ;+1$ bis +3

PO-Platforma Obywatelska - Bürgerplattform; PiS - Prawo i Sprawiedliwość-Recht und Gerechtigkeit; SLD - Sojusz Lewicy Demokratycznej - Demokratische Linksallianz; PSL - Polskie Stronnictwo Ludowe - Polnische Bauernpartei

Quelle: CBOS BS/56/2012 Reprezentatywność partii politycznych [Die Repräsentativität der politischen Parteien]. Warszawa 04/2012. www.cbos.pl 


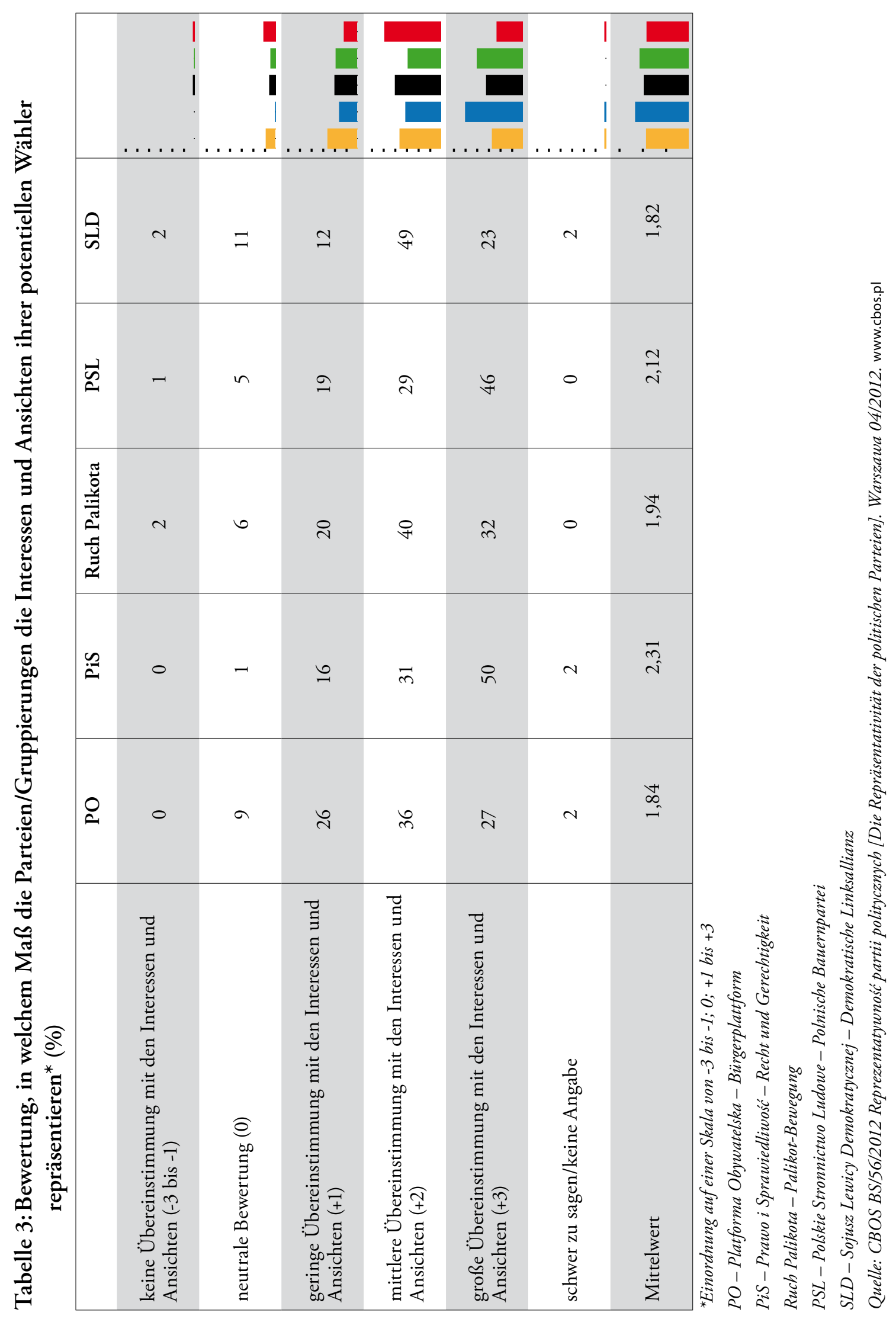


Tabelle 4: In welchem Maß repräsentiert die Palikot-Bewegung (Ruch Palikota) Ihre Interessen und Ansichten?* (\%)

\begin{tabular}{|l|c|c|c|c|c|}
\hline & PO-Wähler & PSL-Wähler & PiS-Wähler & $\begin{array}{c}\text { Wähler von } \\
\text { Ruch Palikota }\end{array}$ & SLD-Wähler \\
$\begin{array}{l}\text { keine Übereinstim- } \\
\text { mung mit den Interes- } \\
\text { sen und Ansichten (-3 } \\
\text { bis -1) }\end{array}$ & 46 & 68 & 73 & 2 & 37 \\
$\begin{array}{l}\text { neutrale Bewertung (0) } \\
\begin{array}{l}\text { Übereinstimmung mit } \\
\text { den Interessen und } \\
\text { Ansichten (+1 bis +3) }\end{array}\end{array} \quad 23$ & 21 & 16 & 6 & 35 \\
\hline $\begin{array}{l}\text { schwer zu sagen/keine } \\
\text { Kenntnis }\end{array}$ & 5 & 2 & 5 & 92 & 5 \\
\hline
\end{tabular}

*Einordnung auf einer Skala von -3 bis $-1 ; 0 ;+1$ bis +3

PO-Platforma Obywatelska - Bürgerplattform; PSL - Polskie Stronnictwo Ludowe-Polnische Bauernpartei; PiS - Prawo i Sprawiedliwość-Recht und Gerechtigkeit; Ruch Palikota-Palikot-Bewegung; SLD-Sojusz Lewicy Demokratycznej-Demokratische Linksallianz Quelle: CBOS BS/56/2012 Reprezentatywność partii politycznych [Die Repräsentativität der politischen Parteien]. Warszawa 04/2012. www.cbos.pl

Tabelle 5: In welchem Maß repräsentiert die Bürgerplattform (PO) Ihre Interessen und Ansichten?* (\%)

\begin{tabular}{|l|c|c|c|c|c|}
\hline & PO-Wähler & PSL-Wähler & PiS-Wähler & $\begin{array}{c}\text { Wähler von } \\
\text { Ruch Palikota }\end{array}$ & SLD-Wähler \\
$\begin{array}{l}\text { keine Übereinstim- } \\
\text { mung mit den Interes- } \\
\text { sen und Ansichten (-3 } \\
\text { bis -1) }\end{array}$ & 0 & 42 & 75 & 38 & 47 \\
\hline $\begin{array}{l}\text { neutrale Bewertung (0) } \\
\begin{array}{l}\text { Übereinstimmung mit } \\
\text { den Interessen und } \\
\text { Ansichten (+1 bis +3) }\end{array}\end{array} \quad 89$ & 33 & 13 & 26 & 21 \\
\hline $\begin{array}{l}\text { schwer zu sagen/keine } \\
\text { Kenntnis }\end{array}$ & 2 & 0 & 4 & 36 & 0 \\
\hline
\end{tabular}

${ }^{*}$ Einordnung auf einer Skala von -3 bis $-1 ; 0 ;+1$ bis +3

PO-Platforma Obywatelska - Bürgerplattform; PSL - Polskie Stronnictwo Ludowe - Polnische Bauernpartei; PiS - Prawo i Sprawiedliwość-Recht und Gerechtigkeit; Ruch Palikota - Palikot-Bewegung; SLD - Sojusz Lewicy Demokratycznej-Demokratische Linksallianz Quelle: CBOS BS/56/2012 Reprezentatywność partii politycznych [Die Repräsentativität der politischen Parteien]. Warszawa 04/2012. www.cbos.pl 
Tabelle 6: In welchem Maß repräsentiert Recht und Gerechtigkeit (PiS) Ihre Interessen und Ansichten?* (\%)

\begin{tabular}{|l|c|c|c|c|c|}
\hline & PO-Wähler & PSL-Wähler & PiS-Wähler & $\begin{array}{c}\text { Wähler von } \\
\text { Ruch Palikota }\end{array}$ & SLD-Wähler \\
$\begin{array}{l}\text { keine Übereinstim- } \\
\text { mung mit den Interes- } \\
\text { sen und Ansichten (-3 } \\
\text { bis -1) }\end{array}$ & 70 & 42 & 0 & 84 & 68 \\
$\begin{array}{l}\text { neutrale Bewertung (0) } \\
\text { Übereinstimmung mit } \\
\text { den Interessen und } \\
\text { Ansichten (+1 bis +3) }\end{array}$ & 15 & 31 & 1 & 11 & 15 \\
\hline $\begin{array}{l}\text { schwer zu sagen/keine } \\
\text { Kenntnis }\end{array}$ & 3 & 24 & 97 & 5 & 0 \\
\hline
\end{tabular}

*Einordnung auf einer Skala von -3 bis $-1 ; 0 ;+1$ bis +3

PO-Platforma Obywatelska-Bürgerplattform; PSL - Polskie Stronnictwo Ludowe - Polnische Bauernpartei; PiS-Prawo i Sprawiedliwość-Recht und Gerechtigkeit; Ruch Palikota-Palikot-Bewegung; SLD-Sojusz Lewicy Demokratycznej-Demokratische Linksallianz Quelle: CBOS BS/56/2012 Reprezentatywność partii politycznych [Die Repräsentativität der politischen Parteien]. Warszawa 04/2012. www.cbos.pl

Tabelle 7: In welchem Maß repräsentiert die Demokratische Linksallianz (SLD) Ihre Interessen und Ansichten?* (\%)

\begin{tabular}{|c|c|c|c|c|c|}
\hline & PO-Wähler & PSL-Wähler & PiS-Wähler & $\begin{array}{c}\text { Wähler von } \\
\text { Ruch Palikota }\end{array}$ & SLD-Wähler \\
\hline $\begin{array}{l}\text { keine Übereinstim- } \\
\text { mung mit den Interes- } \\
\text { sen und Ansichten (-3 } \\
\text { bis -1) }\end{array}$ & 29 & 31 & 51 & 27 & 2 \\
\hline neutrale Bewertung (0) & 32 & 39 & 23 & 26 & 11 \\
\hline $\begin{array}{l}\text { Übereinstimmung mit } \\
\text { den Interessen und } \\
\text { Ansichten }(+1 \text { bis }+3)\end{array}$ & 33 & 27 & 12 & 42 & 84 \\
\hline $\begin{array}{l}\text { schwer zu sagen/keine } \\
\text { Kenntnis }\end{array}$ & 6 & 3 & 13 & 5 & 3 \\
\hline
\end{tabular}

*Einordnung auf einer Skala von -3 bis $-1 ; 0 ;+1$ bis +3

PO-Platforma Obywatelska - Bürgerplattform; PSL - Polskie Stronnictwo Ludowe - Polnische Bauernpartei; PiS - Prawo i Sprawiedliwość-Recht und Gerechtigkeit; Ruch Palikota - Palikot-Bewegung; SLD-Sojusz Lewicy Demokratycznej-Demokratische Linksallianz Quelle: CBOS BS/56/2012 Reprezentatywność partii politycznych [Die Repräsentativität der politischen Parteien]. Warszawa 04/2012. www.cbos.pl 


\section{Einstellungen zur Regierung Tusk (Frühjahr 2012)}

Grafik 1: Das Verhältnis zur PO-PSL-Regierung von Ministerpräsident Donald Tusk (\%)

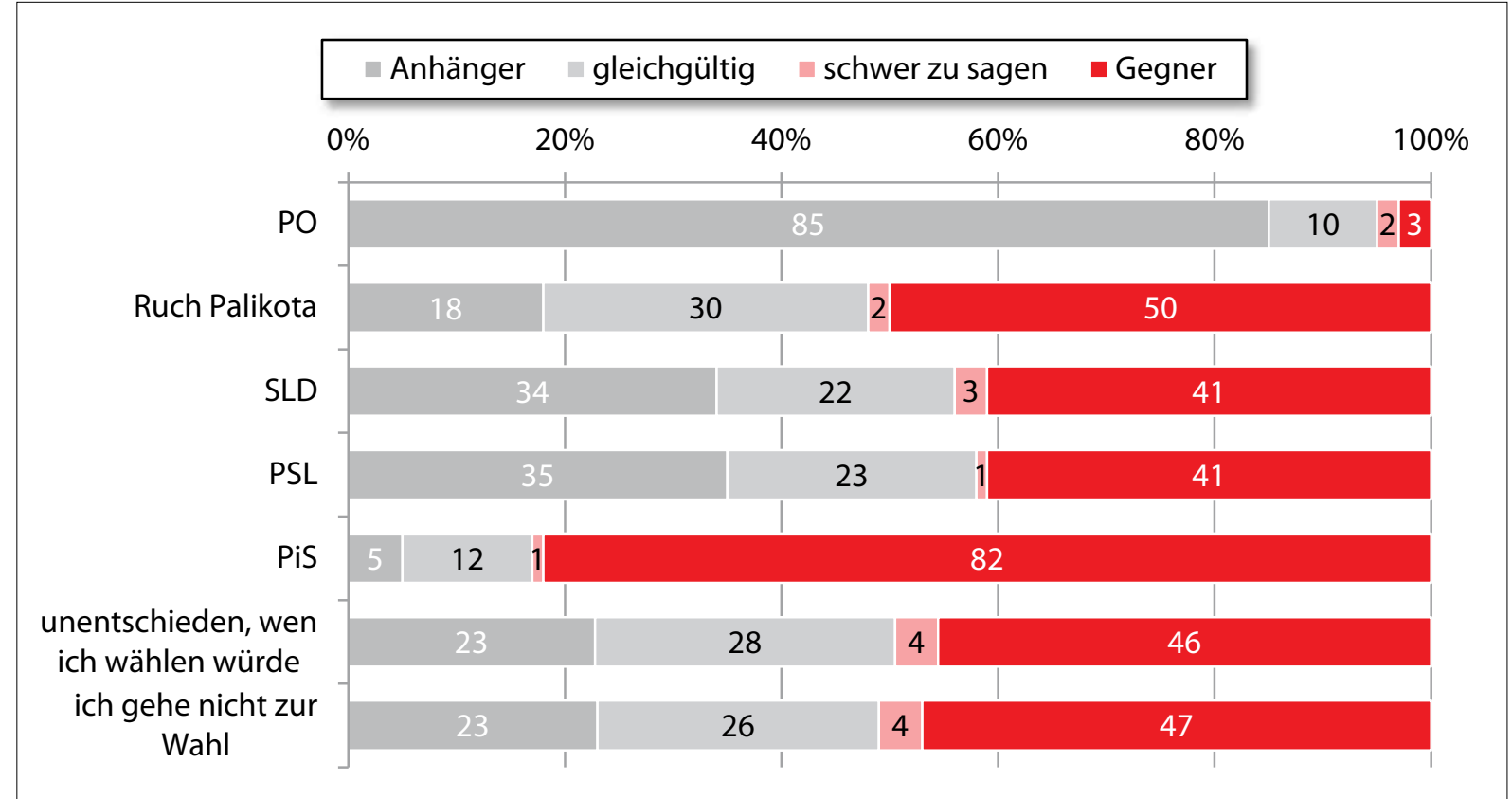

PO-Platforma Obywatelska - Bürgerplattform; Ruch Palikota-Palikot-Bewegung; SLD - Sojusz Lewicy Demokratyzcnej-Demokratische Linksallianz; PSL - Polskie Stronnictwo Ludowe-Polnische Bauernpartei; PiS-Prawo i Sprawiedliwość-Recht und Gerechtigkeit Quelle: CBOS, BS/41/2012 Stosunek do rzadu w marcu [Das Verhältnis zur Regierung im März]. Warszawa $03 / 2012$

Grafik 2: Sind Sie zufrieden, dass an der Spitze der Regierung Donald Tusk (PO) steht? (\%)

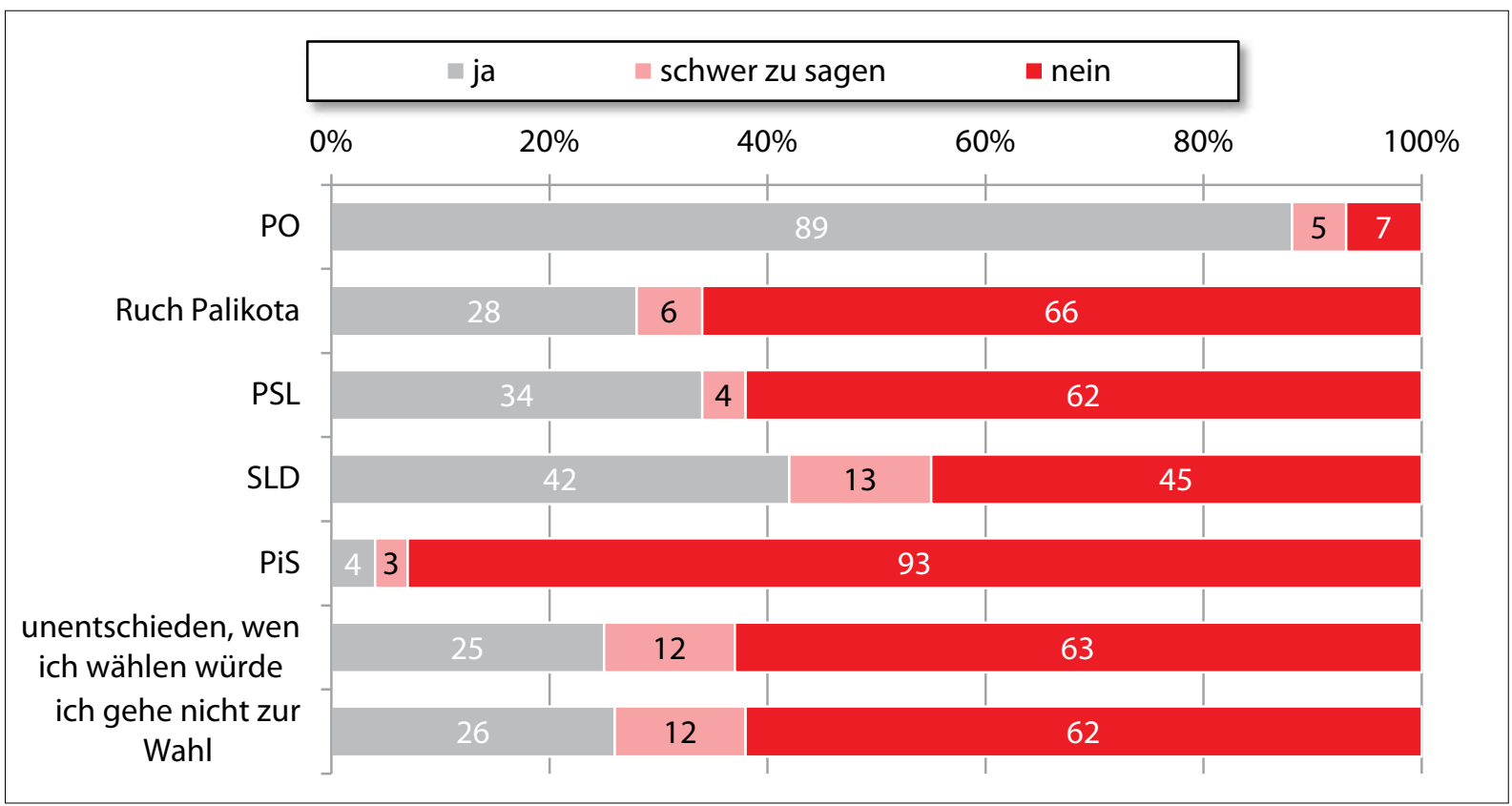

PO-Platforma Obywatelska-Bürgerplattform; Ruch Palikota-Palikot-Bewegung; SLD-Sojusz Lewicy Demokratyzcnej-Demokratische Linksallianz; PSL - Polskie Stronnictwo Ludowe-Polnische Bauernpartei; PiS-Prawo i Sprawiedliwość-Recht und Gerechtigkeit Quelle: CBOS, BS/41/2012 Stosunek do rzadu w marcu [Das Verhältnis zur Regierung im März]. Warszawa 03/2012 


\section{Grafik 3: Die Beurteilung der Wirtschaftspolitik der PO-PSL-Regierung von Ministerpräsident Donald Tusk (\%)}

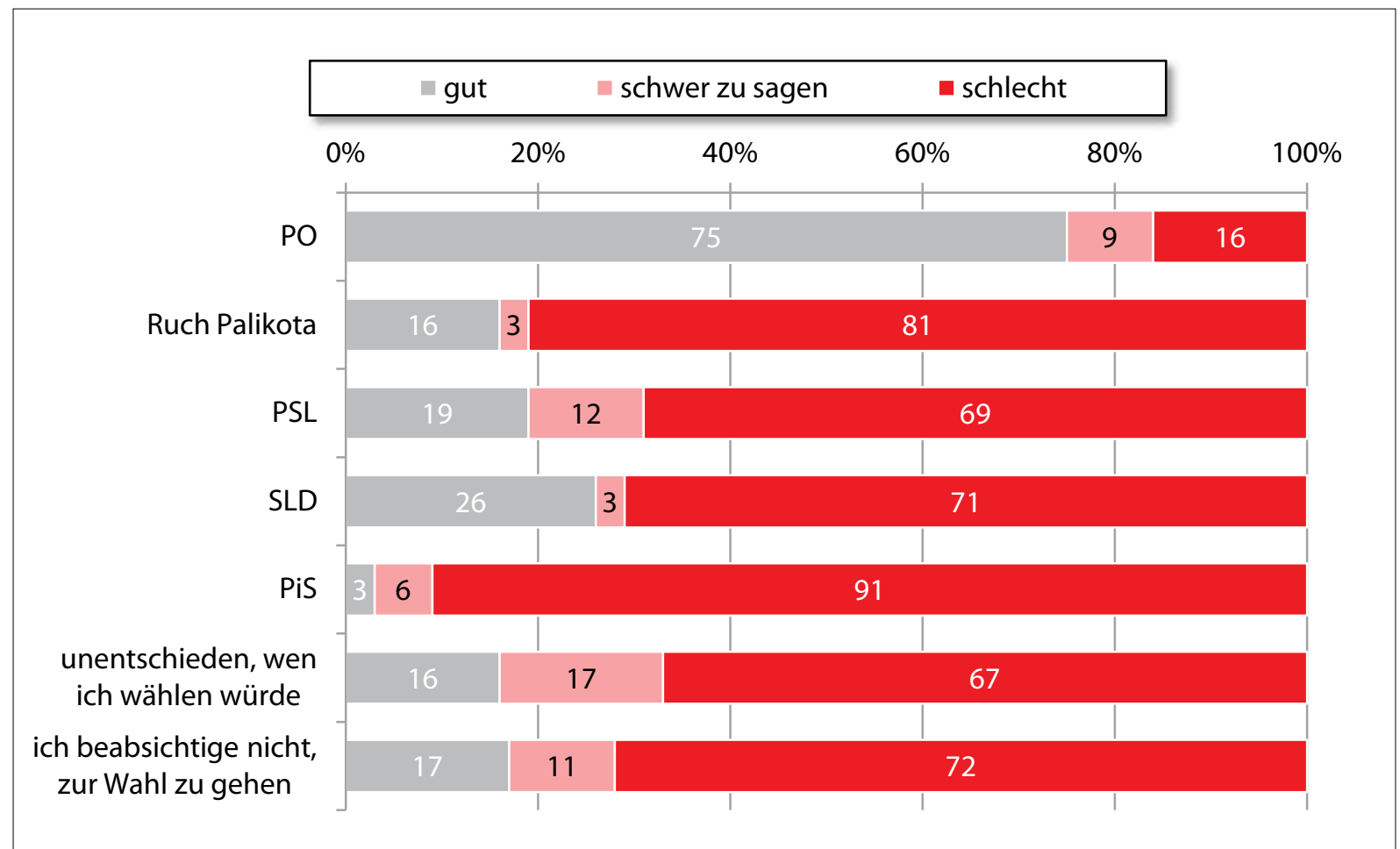

PO-Platforma Obywatelska-Bürgerplattform; Ruch Palikota-Palikot-Bewegung; SLD-Sojusz Lewicy Demokratyzcnej-Demokratische Linksallianz; PSL - Polskie Stronnictwo Ludowe-Polnische Bauernpartei; PiS-Prawo i Sprawiedliwość-Recht und Gerechtigkeit Quelle: CBOS, BS/41/2012 Stosunek do rzadu w marcu [Das Verhältnis zur Regierung im März]. Warszawa $03 / 2012$

\section{CHRONIK}

\section{Vom 17. bis zum 30. April 2012}

\begin{tabular}{|l|l|}
\hline 17.04.2012 & $\begin{array}{l}\text { Der ehemalige Sportminister in der Regierung von Jarosław Kaczyński (Recht und Gerechtigkeit/Prawo i Spra- } \\
\text { wiedliwość-PiS), Tomasz Lipiec, wird wegen Bestechlichkeit zu dreieinhalb Jahren Haft verurteilt. Seine Anwälte } \\
\text { kündigen Berufung an. }\end{array}$ \\
\hline 18.04 .2012 & $\begin{array}{l}\text { Die Chefin des Internationalen Währungsfonds (IWF), Christine Lagarde, zeigt sich zufrieden, dass Polen den } \\
\text { IWF mit 6,27 Mrd. Euro unterstützen wird. Die Polnische Nationalbank (Narodowy Bank Polski - NBP) teilt } \\
\text { mit, dass die endgültige Entscheidung nach der Vereinbarung der Vertragsbedingungen mit dem IWF fallen wird. }\end{array}$ \\
\hline 19.04 .2012 & $\begin{array}{l}\text { Am Rande des Treffens der Umweltminister der EU-Mitgliedsländer in Horsens (Dänemark) spricht sich Umwelt- } \\
\text { minister Marcin Korolec gegen die Kostenerhöhung des EU-Emissionshandels (EU Emission Trading System) } \\
\text { über die Verringerung der Anzahl der Emissionszertifikate aus. Die Europäische Kommission hatte eine solche } \\
\text { Vorgehensweise in Aussicht gestellt, um umweltfreundliche Energieinvestitionen zu fördern. }\end{array}$ \\
\hline
\end{tabular}




\begin{tabular}{|c|c|}
\hline 20.04.2012 & $\begin{array}{l}\text { Im Sejm findet eine Konferenz der Parlamentspräsidenten der EU-Mitgliedsländer statt. Ministerpräsident Donald } \\
\text { Tusk mahnt in seiner Rede an, dass sich die EU nicht von ihren Werten und Errungenschaften abwenden darf. } \\
\text { Derzeit würde die politische Begründung der Existenz der Europäischen Union von manchen in Zweifel gezogen. } \\
\text { Die EU müsse aber weiter den Weg der Integration gehen. Die Konferenz ist das letzte parlamentarische Treffen } \\
\text { im Zusammenhang mit der polnischen EU-Ratspräsidentschaft in der zweiten Hälfte 2011. Im weiteren Verlauf } \\
\text { einigen sich die Teilnehmer darauf, eine interparlamentarische Konferenz einzurichten, die die parlamentarische } \\
\text { Kontrolle über die gemeinsame Außen- und Sicherheitspolitik sowie Sicherheits- und Verteidigungspolitik über- } \\
\text { nehmen soll. Entsandt werden sollen Abgeordnete der EU-Mitgliedsstaaten, des Europäischen Parlaments sowie } \\
\text { der EU-Kandidatenländer und der europäischen NATO-Länder außerhalb der EU. }\end{array}$ \\
\hline 21.04.2012 & $\begin{array}{l}\text { Auf einer Kundgebung in Warschau gegen die Verweigerung der digitalen Sendelizenz für den katholischen Sen- } \\
\text { der »TV Trwam»ruft der Parteivorsitzende von Recht und Gerechtigkeit (Prawo i Sprawiedliwość-PiS), Jarosław } \\
\text { Kaczyński, seinen Amtskollegen von »Solidarisches Polen von Zbigniew Ziobro» (Solidarna Polska Zbigniewa } \\
\text { Ziobry), Zbigniew Ziobro, auf, zur PiS zurückzukehren, um eine Einheit des rechtskonservativen politischen } \\
\text { Spektrums wiederherzustellen. An der Kundgebung nehmen mehrere Tausend Menschen teil. }\end{array}$ \\
\hline 22.04 .2012 & $\begin{array}{l}\text { Dem Senator Stanisław Gogacz (Recht und Gerechtigkeit/Prawo i Sprawiedliwość - PiS) wird die Einreise nach } \\
\text { Belarus zu einer Kulturveranstaltung der dortigen Polonia verwehrt. Gründe werden nicht angegeben. }\end{array}$ \\
\hline 24.04 .2012 & $\begin{array}{l}\text { Ministerpräsident Donald Tusk beendet seinen viertägigen Besuch auf der Arabischen Halbinsel. Einer der Haupt- } \\
\text { programmpunkte war die Teilnahme am Polnisch-Saudischen Businessforum in Riad (Saudi-Arabien). Tusk zeigt } \\
\text { sich zuversichtlich, dass es in absehbarer Zeit zu dem ersten umfangreicheren Ankauf saudischen Erdöls kommen } \\
\text { wird. Dies sei wichtig in Hinblick auf eine Diversifizierung des polnischen Energiemarktes. }\end{array}$ \\
\hline 24.04 .2012 & $\begin{array}{l}\text { Der Parteivorsitzende von "Solidarisches Polen von Zbigniew Ziobro" (Solidarna Polska Zbigniewa Ziobry) } \\
\text { schreibt einen offenen Brief an den Parteivorsitzenden von Recht und Gerechtigkeit (Prawo i Sprawiedliwość- } \\
\text { PiS), Jarosław Kaczyński. Eine Rückkehr von "Solidarisches Polen« zu PiS sei von der Demokratisierung von } \\
\text { PiS, von der faktischen Umsetzung des Programms "Solidarischer Staat« und von der Mäßigung der Rhetorik } \\
\text { bei der Aufklärung der Flugzeugkatastrophe von Smolensk abhängig. Hintergrund ist die öffentliche Aufforde- } \\
\text { rung Kaczyńskis an Ziobro in der vergangenen Woche, zu PiS zurückzukehren. }\end{array}$ \\
\hline 25.04 .2012 & $\begin{array}{l}\text { Ministerpräsident Donald Tusk empfängt seinen chinesischen Amtskollegen Wen Jiabao, der zum ersten offiziel- } \\
\text { len Besuch eines chinesischen Regierungschefs seit } 25 \text { Jahren in Polen eingetroffen ist. Tusk betont das Interesse } \\
\text { Polens an einem verstärkten Engagement chinesischer Investoren in Polen. Dabei sei auch über eine Zusammen- } \\
\text { arbeit im Bereich alternativer Energien, insbesondere bei der Förderung von Schiefergas, gesprochen worden, so } \\
\text { Tusk. Er habe außerdem unterstrichen, dass der Aufbau eines modernen Staates und einer Bürgergesellschaft } \\
\text { stark mit dem Schutz der Rechte und Freiheiten der Bürger verknüpft sind. Am Folgetag wird in Warschau von } \\
\text { beiden Regierungschefs das Wirtschaftsforum Polen-Mitteleuropa-China eröffnet werden. }\end{array}$ \\
\hline 26.04 .2012 & $\begin{array}{l}\text { Der Abgeordnete der Demokratischen Linksallianz (Sojusz Lewicy Demokratycznej-SLD), Witold Klepacz, tritt } \\
\text { zur Partei Palikot-Bewegung (Ruch Palikota) über. Seiner Einschätzung nach weist die Palikot-Bewegung ein großes } \\
\text { Potential auf und könnte eine Alternative zur aktuellen Regierung werden, während die SLD aus ihrer jahrelangen } \\
\text { Krise nicht herauskomme. Klepacz will für die Zusammenarbeit zwischen Palikot-Bewegung und SLD eintreten. }\end{array}$ \\
\hline 27.04 .2012 & $\begin{array}{l}\text { Der Sejm lehnt einen Antrag ab, die weitere Arbeit des Sonderausschusses am Gesetzentwurf der Regierung zur } \\
\text { Rentenreform einzustellen. Der Antrag war von Recht und Gerechtigkeit (Prawo i Sprawiedliwość - PiS), der } \\
\text { Demokratischen Linksallianz (Sojusz Lewicy Demokratycznej - SLD) und "Solidarisches Polen von Zbigniew } \\
\text { Ziobro« (Solidarna Polska Zbigniewa Ziobry) eingebracht worden. }\end{array}$ \\
\hline 28.04 .2012 & $\begin{array}{l}\text { Leszek Miller wird auf dem Parteitag der Demokratischen Linksallianz (Sojusz Lewicy Demokratycznej - SLD) } \\
\text { in seinem Amt als Parteivorsitzender bestätigt. }\end{array}$ \\
\hline 29.04 .2012 & $\begin{array}{l}\text { Den Vorschlag von Janusz Palikot, Parteivorsitzender der Palikot-Bewegung (Ruch Palikota), gemeinsam einen } \\
\text { starken linken Block zu bilden, mit dem Ziel, den politischen Einfluss von Bürgerplattform (Platforma Obywatel- } \\
\text { ska - PO) und von Recht und Gerechtigkeit (Prawo i Sprawiedliwość - PiS) zu verringern, lehnt der Parteivorsit- } \\
\text { zende der Demokratischen Linksallianz (Sojusz Lewicy Demokratycznej - SLD), Leszek Miller, mit der Begrün- } \\
\text { dung ab, dass die Palikot-Bewegung zur Mitte-Rechts-Regierungskoalition aus Bürgerplattform (Platforma Oby- } \\
\text { watelska - PO) und Polnischer Bauernpartei (Polskie Stronnictwo Ludowe - PSL) gehöre. Die Politik dieses drei- } \\
\text { gliedrigen Bündnisses sei von Grund auf gegen die Arbeitnehmer und die Linke gerichtet. }\end{array}$ \\
\hline 30.04 .2012 & $\begin{array}{l}\text { Der Sprecher der Europäischen Kommission stellt eine Intervention der Europäischen Kommission in Aussicht, soll- } \\
\text { ten Polen und Tschechien ihren Streit in der sogenannten Salzaffäre nicht beenden. Hintergrund ist, dass in Polen } \\
\text { Industriesalz als Speisesalz verkauft worden war. Daraufhin hatte Tschechien zeitweise den Salzimport aus Polen } \\
\text { eingestellt und Aufklärung von Polen verlangt. Diese ist nach Auffassung des tschechischen Landwirtschaftsmi- } \\
\text { nisters Petr Bendl nicht in ausreichendem Maße erfolgt, weshalb sich Tschechien an die EU-Kommission wandte. }\end{array}$ \\
\hline
\end{tabular}


Die Polen-Analysen erscheinen zweimal monatlich als E-Mail-Dienst. Sie werden gemeinsam vom Deutschen PolenInstitut Darmstadt, der Bremer Forschungsstelle Osteuropa und der Deutschen Gesellschaft für Osteuropakunde herausgegeben.

Ein Archiv der Polen-Analysen finden Sie im Internet unter www.laender-analysen.de/polen

Kostenloses Abonnement unter http://www.deutsches-polen-institut.de/Newsletter/subscribe.php

Diese Analysen finden Sie online als Lizenzausgabe auf

bpb.de

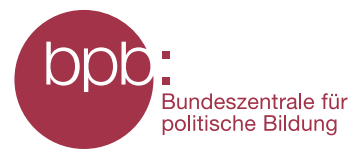

\section{Deutsches Polen-Institut Darmstadt}

Das Deutsche Polen-Institut Darmstadt (DPI) ist ein Forschungs-, Informations-, und Veranstaltungszentrum für polnische Kultur, Geschichte, Politik, Gesellschaft und die deutsch-polnischen Beziehungen, die sich im Kontext der europäischen Integration entwickeln. Das seit März 1980 aktive und bis 1997 von Gründungsdirektor Karl Dedecius geleitete Institut ist eine Gemeinschaftsgründung der Stadt Darmstadt, der Länder Hessen und Rheinland-Pfalz sowie des Bundes. 1987 wurden die Kultusminister der Länder und 2011 das Auswärtige Amt weitere institutionelle Träger. Einen wesentlichen Beitrag zur Verwirklichung der Institutsziele leisten private Stiftungen. Das DPI hat satzungsgemäß die Aufgabe, durch seine Arbeit zur Vertiefung der gegenseitigen Kenntnisse des kulturellen, geistigen und gesellschaftlichen Lebens von Polen und Deutschen beizutragen.

Ziel der Vermittlertätigkeit des DPI ist es, »die zu interessieren, auf die es politisch, wirtschaftlich, gesellschaftlich und kulturell im deutsch-polnischen Verhältnis ankommt“ (Leitlinien 1997). Es geht um die Entscheider und Multiplikatoren in Politik, Kultur, Bildung, Verwaltung, Medien und Wirtschaft und, wesentlich stärker ausgeprägt als bisher, um das Hineinwirken in Wissenschaft, Forschung und Bildung.

Derzeit bemüht sich das DPI in Kooperation mit den verstreuten Orten wissenschaftlicher Polen-Kompetenz an deutschen Hochschulen und Forschungsinstituten verstärkt darum, ausgehend von einer Bestandsaufnahme deutscher Polen-Forschung Ort wissenschaftlicher Forschung und verbindendes, vernetzendes und kooperierendes Zentrum zu werden. Ausgangspunkt der Neuausrichtung ist die kaum mehr kontrollierbare Dynamik des Rückbaus der Ressourcen der wissenschaftlichen Polen-Kompetenz in den unterschiedlichen Disziplinen. Mit der über 60.000 Bände zählenden multidisziplinären Fachbibliothek für Polen, die eine einzigartige Sammlung polnischer Literatur in der Originalsprache und in deutscher Übersetzung umfasst, ist das DPI bereits ein geschätzter Ort der Recherche und des wissenschaftlichen Arbeitens. (www.deutsches-polen-institut.de)

\section{Forschungsstelle Osteuropa an der Universität Bremen (www.forschungsstelle.uni-bremen.de)}

1982 gegründet, widmet sich die Forschungsstelle Osteuropa an der Universität Bremen der interdisziplinären Analyse der Länder Ost- und Ostmitteleuropas in Zeitgeschichte und Gegenwart. Der Forschungsschwerpunkt liegt dabei auf der Rolle von "Dissens und Konsens«, von Opposition und Zivilgesellschaft in ihrem historischen, politischen, gesellschaftlichen und kulturellen Kontext. Die Forschungsstelle besitzt in ihrem Archiv eine einzigartige Sammlung alternativer Kulturgüter und unabhängiger Texte aus den ehemaligen sozialistischen Ländern. Darunter befindet sich auch eine umfangreiche Sammlung des "Zweiten Umlaufs», die das Schrifttum und Dokumente unabhängiger Initiativen und gesellschaftlicher Gruppen in Polen aus der Zeit von 1976 bis zum Umbruch umfasst. Hinzu kommt eine umfangreiche Bibliothek mit wissenschaftlicher Literatur. Mit Archiv, Bibliothek und zwei wissenschaftlichen Abteilungen ist die Forschungsstelle auch eine Anlaufstelle sowohl für Gastwissenschaftler als auch für die interessierte Öffentlichkeit.

Eine der Hauptaufgaben der Forschungsstelle ist die Information der interessierten Öffentlichkeit. Dazu gehören unter anderem regelmäßige E-Mail-Informationsdienste für Politik, Wirtschaft, Zivilgesellschaft und Medien. 